\title{
MGNREGA: A step towards improving livelihood security of women in rural areas
}

ABSTRACT : The present study was conducted in Faizabad district of Uttar Pradesh. The purpose of the present study was to find out improvement in life of rural women through MGNREGA. The sample consisted of 100 randomly selected respondents from two panchayat samities. Personal interview technique was used for collecting data. Findings of the study reveal that MGNREGA: improved the life of rural women in terms of their income and employment

KEY WORDS: Employment, Income, Benefits, MGNREGA

- HOW TO CITE THIS PAPER : Tiwari, Neha and Vyas, Jiju N. (2016). MGNREGA: A step towards improving livelihood security of women in rural areas. Asian J. Home Sci., 11 (1) : 257-260, DOI: 10.15740/ HAS/AJHS/11.1/257-260. 